\title{
Systematic monitoring of the deformed state of long-length reinforced concrete structures with an assessment of their reliability
}

\author{
Aleksandr Perunov", and Aleksey Baulin \\ Moscow State University of Civil Engineering, Yaroslavskoe shosse, 26, Moscow, 129337, Russia
}

\begin{abstract}
The article shows the method of systematic monitoring of the stress-strain state of reinforced concrete structures covering one of the operated public railway stations. The description of large-span structures of the building, their defects and damages acquired during the operation of the building is given. The article describes the methodology and methods used for long-term, more than 2 years, continuous monitoring of the deformed state of coating structures in operation. The most damaged structures are examined in detail with the help of installed devices to obtain accurate data. The features of measurements in different periods of time and time of year are described. Based on the results of the obtained measurements of the stress-strain state of the building coating structures, the possibility of their further operation is predicted, taking into account the defects and damages found during the survey.
\end{abstract}

\section{Introduction}

When operating public buildings with large-span structures, there is a need to monitor the state of the structures. This is especially true of modern buildings with large spans of enclosing structures and their complex cross-section and unique design. These types of buildings include, for example, waiting rooms at suburban train stations. These buildings usually have a unique configuration of some building structures, for example, because of their architectural features. In this regard, during their design and manufacture, preliminary tests of these unique structures are carried out. With successful results of these tests, the designs are allowed to be produced. But over time, destructive processes occur in the building structure itself with a unique design. For example, if it is a reinforced concrete prestressed structure that works for bending, these processes include damage to the protective layer of concrete, cracks, corrosion of the reinforcement, loss of prestressed reinforcement, which in turn leads to increased deflections of the structure itself. The processes that take place in the structure itself during its operation will depend on many factors over time, such as the quality of project documentation, construction, installation, operating conditions, etc. In this regard, there is a need to monitor the operation of the structure in real conditions during the entire period of its operation. There is also the

*Corresponding author: PerunovAS@mgsu.ru 
question of assessing their reliability and suitability for further use. To do this, it is necessary to regularly, preferably for a long time, monitor the operation of the structure. This should be done taking into account its actual operating conditions.

As an example of solving this problem, this article discusses the construction of the railway passenger waiting room cover. A diagram of this building is shown in Fig. 1.

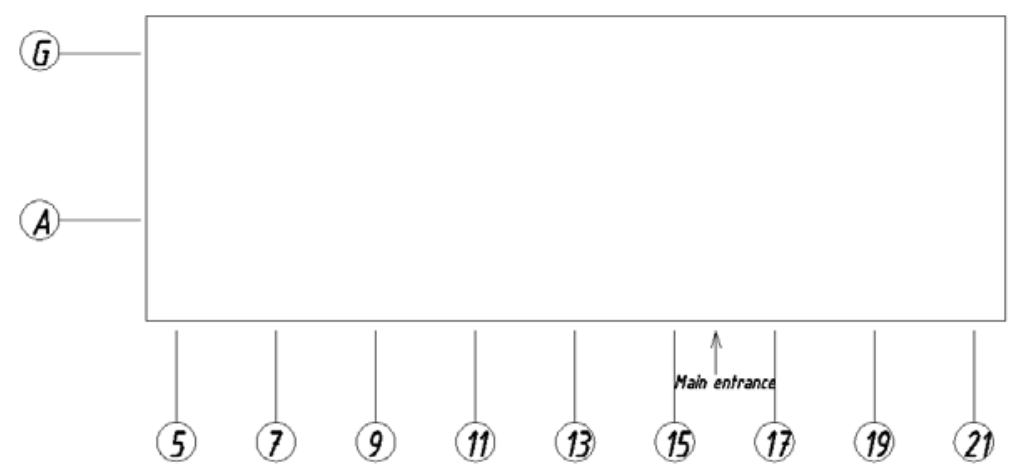

Fig. 1. Diagram of the railway station building under study.

The station building under study is part of an ensemble consisting of several buildings, so it has a designation in the axes 5-21/A-G. It is a one-story building with a basement and mezzanines on the 1st floor level. The building is rectangular in shape with a roof area of $195 \times 45 \mathrm{~m}$. The load-bearing structures of the building are made of precast reinforced concrete structures. The first floor is an architectural volume formed by a roof of U-shaped precast concrete elements, glass stained glass windows, etc. (Fig. 2).

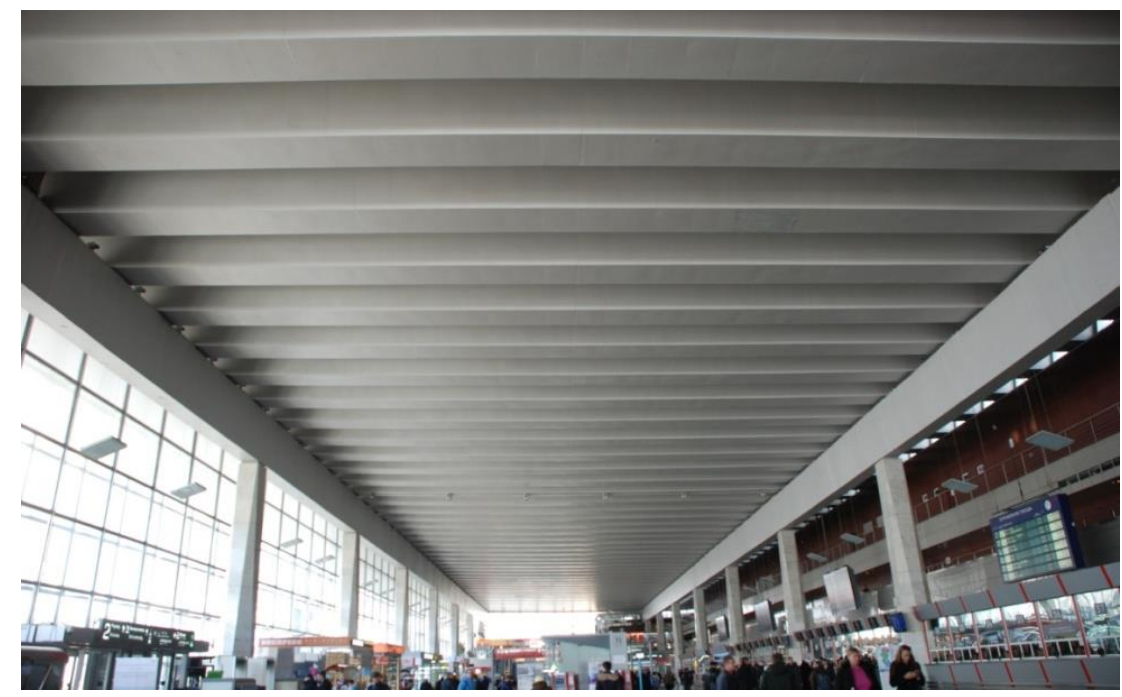

Fig. 2. General view of the load-bearing structures of the station building at the 1st floor level.

The main load-bearing structures of the first floor are two reinforced concrete multispan frames located along the longitudinal axes (A and D) of the building, and reinforced concrete U-shaped coating elements laid on top of the frame crossbars in the transverse direction. Fig. 3 and 4 show fragments of the longitudinal and cross-section of the building for clarity 


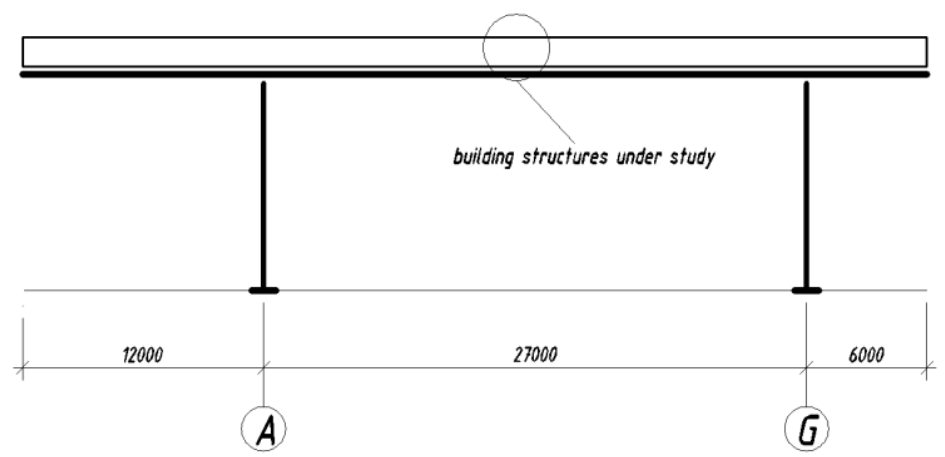

Fig. 3. Cross-section of the station building

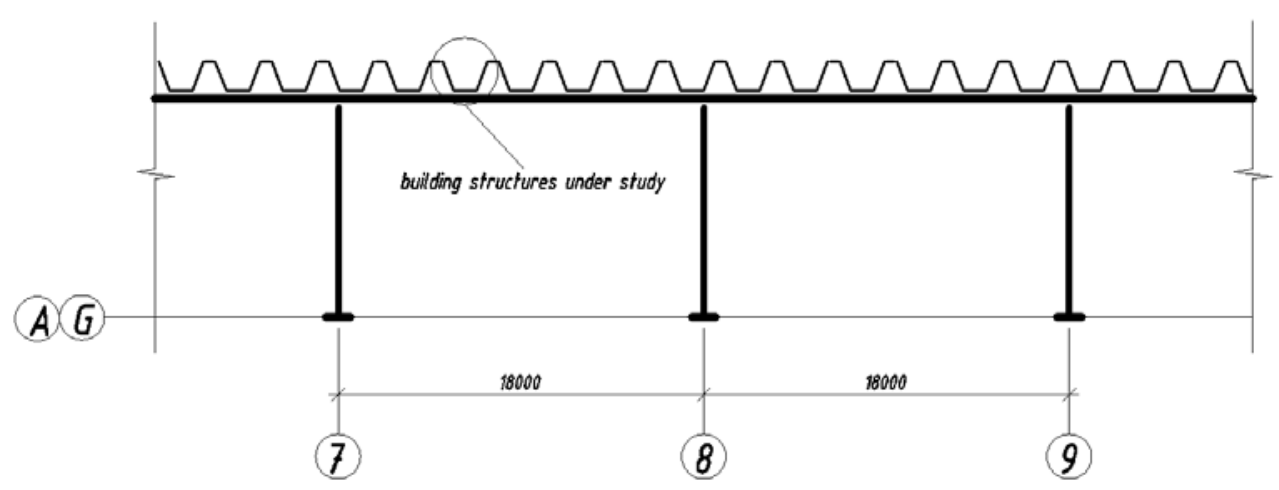

Fig. 4. Fragment of the longitudinal section of the building on the axis 7-9

The building is built on reinforced concrete foundations, united by tape grillages. The columns of the frames are cast-in-place reinforced concrete, of a complex, geometrically variable cross-section in height, with a metal core made of rolled profile. Each frame has 11 columns set in $18 \mathrm{~m}$ increments. The connection of columns and crossbars is rigid, with the establishment of the metal core of the column to the top of the crossbar. The height of the columns from the floor level of the first floor is $10.9 \mathrm{~m}$ along the main facade of the building (axis A) and $10.2 \mathrm{~m}$ in the part adjacent to the old building (axis $\mathrm{G}$ ).

Frame crossbars are cast-in-place reinforced concrete, trapezoidal section, $2.3 \mathrm{~m}$ high. The reach of the crossbar consoles from the extreme axes 5 and 25 is $7.5 \mathrm{~m}$.

U-shaped coating elements ( 66 pieces in total) of open trapezoidal cross-section $(\mathrm{h}=1.48$ $\mathrm{m}$ ) are made of pre-stressed reinforced concrete in the form of a beam structure (Fig.5). The design scheme of the U-shaped elements of the coating is a single-span double-console with a hinged support. Length pleats a $-45 \mathrm{~m}$, length of the span part - $27 \mathrm{~m}$, length of cantilever parts on the main facade of the building is $12 \mathrm{~m}$, on the side adjacent to the old building is 6 $\mathrm{m}$. To increase the rigidity of the coating, the U-shaped elements are connected to each other along the top with monolithic reinforced concrete dowels. According to the project, U-shaped coating elements were manufactured on the construction site. After manufacturing, The U-shaped coating element was loosened along the length by metal ties, raised on the crossbar and moved to the installation site on special rollers. Dismantling of metal ties according to the project was to be carried out after the set of $70 \%$ strength of concrete dowels. 


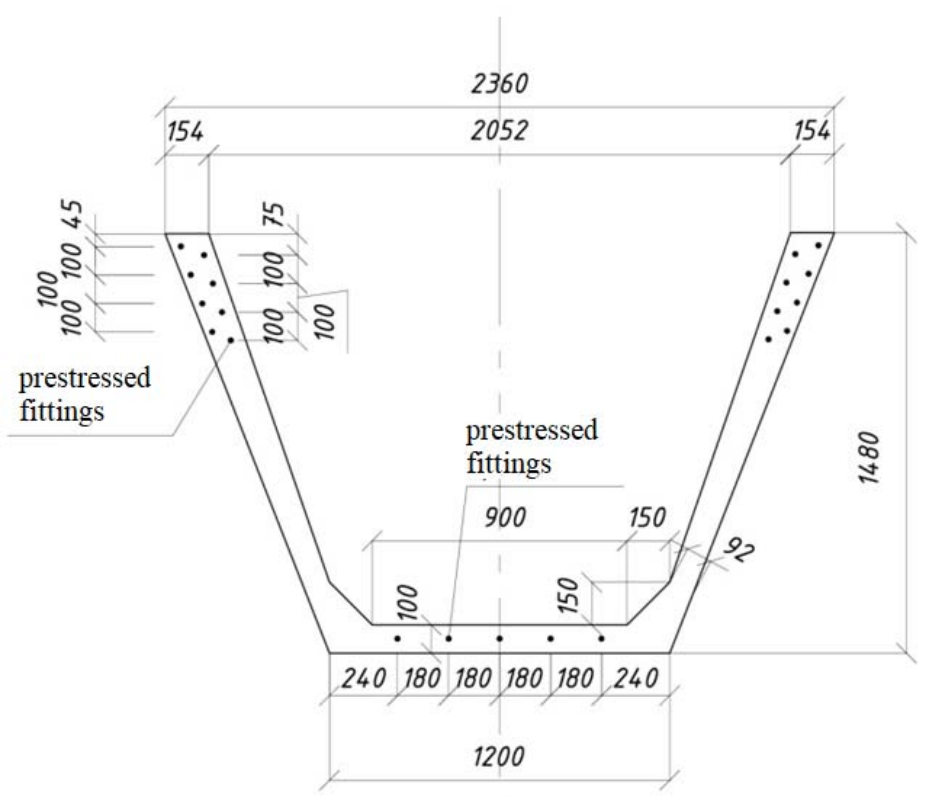

Fig. 5. Cross section of the U-shaped element of the coating structure.

During the operation of the building since 1972, many defects and damages have accumulated on the U-shaped elements of building structures. Basically, the defects are presented in the following form:

- traces of wetting of concrete and damage to the finishing layers on the lower edges of the coating due to leaks from the roof;

- surface corrosion of steel prestressed reinforcement at the ends of the coating in the floor and walls;

- wetting and damage to the protective layer of concrete in the lower part of the coating with the formation of moss on their surfaces as a result of regular leaks from the roof.;

- chipping, damage to the protective layer of concrete, exposure and corrosion of the terminals of the additional mesh reinforcement of the bottom and walls of the coating as a result of regular wetting;

- chipped protective layer of concrete covering the interior of the building, traces of leaks, damage and finishing layers;

- crack opening width $0.1-0.15 \mathrm{~mm}$ of the protective layer of concrete in the lower part of the coating due to wetting due to frequent leaks from the roof;

- the deflection of individual U-shaped elements of the cover is higher than the permissible standard values.

Based on the results of the engineering survey, it was decided to conduct systematic monitoring of the deformed state of the coating structures and assess their reliability.

\section{Materials and methods}

Due to the fact that it was supposed to perform long-term, for 2 years, observations of the deformed state of damaged elements, it was decided to use non-volatile mechanical devices. In the course of scientific research, hour-type indicators were installed in their design sections to monitor the deformations of the most damaged u-shaped coating elements. Given that the building has a total of 66 standard U-shaped structures, it was decided to number them all before testing, and assigning them numbers from № 1 to № 66 . 
Two indicators with a division price of $0.001 \mathrm{~mm}$ were installed on the bottom of element № 18 under the lower row of fittings at the point of passage of cracks with the maximum opening width and height of development. One indicator with a division price of $0.002 \mathrm{~mm}$ was installed on the bottom of element № 21 under the extreme armature at the right wall, also at the point where the most developed crack passes. On the bottom of element №43, which has no cracks, strictly in the section with the maximum span moment under the extreme armature at the left wall, one indicator was also installed with a division price of $0.002 \mathrm{~mm}$.

Under the accepted device installation scheme, the strain increments measured in elements №18 and №21 practically correspond to the increments of the crack opening width, and those measured in element №43 correspond to the absolute deformations of the prestressed reinforcement.

The main data collection method used in this paper included:

- systematic monitoring of the deformation of U-shaped structures with the help of devices previously installed on elements № 18, 21 and 43;

- record outdoor air temperature and snow cover height;

- periodic monitoring of the parameters of cracks on the side and lower surfaces of the elements in the places where the devices are installed; 43.

- periodic monitoring of the condition of the devices installed on elements №18, 21 and

The readings of the devices installed on the most damaged elements were systematically taken during the entire observation period for 2 years. Special attention was paid to the instrument readings during heavy snowfalls. The instrument readings were taken either directly, for which the corresponding tower was used, or indirectly using binoculars from the floor level of the hall, since the waiting room was open around the clock for visitors and made it difficult for the tower to move. In the latter case, due to the shaking of the binoculars in the hands, the counts were made approximately, with an accuracy of several divisions. When taking readings with the help of the tower, the condition of the devices was also checked, and if necessary, they were lubricated. In cases where the instrument readings were different from zero, they were usually set to zero when the instruments were examined.

The daily outdoor temperature was recorded in the shade by a thermometer at 13-15 o'clock in the afternoon.

The thickness of the snow cover on the horizontal surface of the earth was determined mainly by direct measurements (up to 12 measurements at a time).

In some cases, the thickness of the snow cover on the horizontal surface of the earth was determined by corresponding recalculation of the thickness of the snow cover recorded directly on the studied elements of the coating.

In cases where the readings on the devices were taken directly with the help of the tower, the cracks located on the bottom and walls of the folds at the location of the devices were simultaneously examined. Such inspections were carried out once three months.

In the course of the conducted studies, no additional increase in the crack opening width $\left(\Delta_{\text {a.crc }}\right)$ and the height of their development $\left(\Delta_{h . c r c}\right)$ was recorded.

To assess the reliability of damaged coating structures and analyze the experimental data obtained, this article assumes the most unfavorable case when the tensile strain of $0.046 \mathrm{~mm}$ recorded in element 21 fully corresponds to an increase in the crack opening width and, consequently, an increase in deformations and stresses in the prestressed reinforcement of the element bottom.. As the main reason for the noticeable increase in deformations and stresses, we hypothetically assume the development of destructive processes predetermined by the influence of the risk factors mentioned earlier and not 
eliminated to date. In this case, the safety margin of the U-shaped structure over the normal span section will decrease. Quantitative evaluation of this reduction is as follows.

In the beginning, we estimate the increment of deformations of the armature of the fold №21 in the section with the crack $\left(\Delta_{\varepsilon s p}\right)$ for this particular case as:

- for short-term load action $\left(a_{c r c}\right)=195.7 \Delta_{\varepsilon s p}$

- for long-term load $\left(a_{c r c}\right)=307.4 \Delta_{\varepsilon s p}$

where $\left(a_{c r c}\right)$ is the opening width of normal cracks.

Since the increase in deformations on the bottom of element 21 corresponding to an increase in the crack opening width by $0.046 \mathrm{~mm}$ has been recorded for a long period of time, use the formula (2).

In this case

$$
\Delta \varepsilon_{\mathrm{sp}}=\mathrm{a}_{\mathrm{crc}} / 307.4=0.046 / 307.4=15 \cdot 10^{-5}
$$

Corresponding to this value of the increment of deformation $\left(\Delta_{\varepsilon s p}\right)$ the increment of stress $\left(\Delta_{\varepsilon s p}\right)$ will be

$$
\Delta \sigma_{\mathrm{sp}}=\mathrm{E}_{\mathrm{sp}} \Delta \varepsilon_{\mathrm{sp}}=1.853 \cdot 10^{5} \cdot 15 \cdot 10^{-5}=27.8 \mathrm{MPa}
$$

The constructions are shown in figure (7).

$$
M, K H M
$$

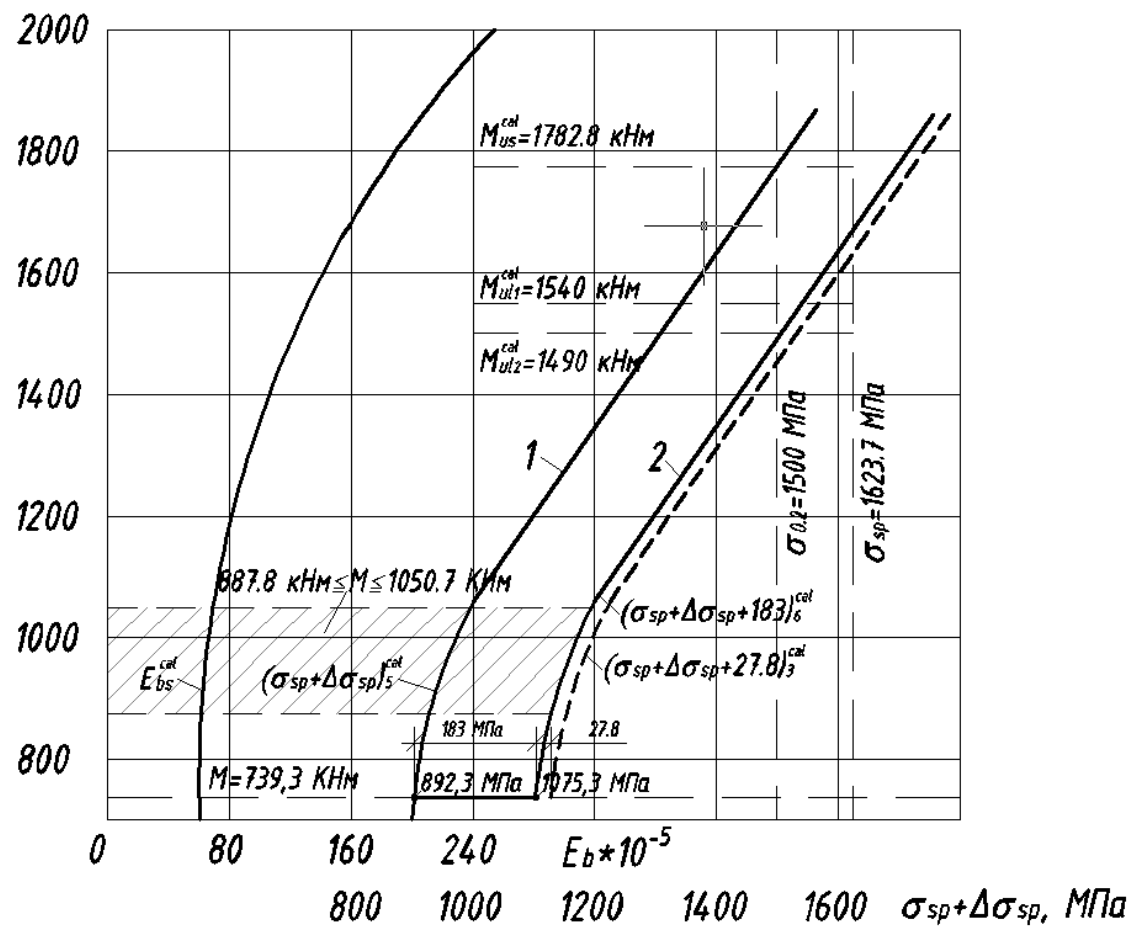

Fig. 7. Determination of the calculated breaking moment $\mathrm{M}_{\mathrm{ul} 2}^{\mathrm{cal}}$ taking into account the stress increment $\Delta_{\sigma \mathrm{sp}}=27.8 \mathrm{MPa}$

\section{Results}

From the results of the calculations, it follows that the stress increment in the prestressed armature of the bottom of element 21 reduces its calculated load-bearing capacity in the span normal section $\left(\mathrm{M}_{\mathrm{us} 2}^{\mathrm{cal}}\right)$ to the value of $1490 \mathrm{kN} * \mathrm{~m}$. The minimum value of the margin coefficient in this case is 


$$
M_{u l 2}^{c a l} / M_{2}^{P}=1490 / 1050.7=1.42
$$

where $\mathrm{M}_{2}^{\mathrm{P}}$ - is the maximum span moment for the calculated value of constant and temporary loads acting on the coating elements.

The resulting value of the reserve coefficient is greater than the regulated GOST 88292018 and equal to 1.3 .

Thus, even in the most unfavorable case, the minimum value of the reserve coefficient of element № 21 is not lower than the normalized value. At the same time, the reserves of increment of deformations and stresses in the pre-armature of the bottom for a long period of time practically did not remain.

\section{Conclusion}

In the course of this research work, a set of observations was carried out on the stress-strain state of the reinforced concrete U-shaped elements of the railway station building covering under snow loads of various intensity and changes in the outdoor air temperature in the range from $+30^{\circ} \mathrm{C}$ to $-25^{\circ} \mathrm{C}$. The analysis and synthesis of the obtained data covering the observation period of 2 years and 1 month was carried out. Based on the research performed, the following main conclusions can be made:

1. in conditions where the main risk factors identified in the course of previous studies continue to have a negative impact on reinforced concrete U-shaped coating elements, systematic instrumental and visual monitoring of their condition is a fairly reliable guarantee against the occurrence of pre-emergency situations.

2. despite the continuing negative impact of risk factors, the minimum safety factor of U-shaped coating elements in the center of the span (according to the normal cross-section) as a result of the study was not lower than the normalized value.

\section{References}

1. Chaika B., Makeev A., Sazonov G., Androsov Y. Complex survey of reinforced concrete structures of the main passenger building of the Kursk railway station.Abstracts of the II international scientific and technical conference "Actual problems of railway transport development (Moscow. MIIT) vol.P (1996).

2. Chaika V. Makeev A. Sazonov G. Androsov Y. The main results of the survey of the reinforced concrete folded covering of the Kursk railway station in Moscow Scientific works of reinforced concrete workers in Siberia and the Urals (Novosibirsk SGAPS) issue 4 (1996).

3. Chaika V. Features of the method of inspection of the folded covering of the station Problems of development of transport and engineering communications. Scientific and technical almanac (M: TIMR Publishing house) no. 3-4 (1996).

4. Chaika V. Diagrammatic methods for examining the folded covering of the station Problems of development of transport and engineering communications. Scientific and technical almanac (M: TIMR Publishing house) no. 5-6 (1996).

5. Eremeev P. G. Experience in the execution of technical monitoring and maintenance of covering structures of unique large-span constructions Industrial and civil construction 2 pp 52-53 (2008).

6. Gorpinchenko V.M., Yegoroy M.I. Monitoring the technical conditions of structures used for socially- significant large-span buildings in Moscow Industrial and civil construction 8 pp 16-19 (2006). 
7. Dorofeev V, Lysov D. Information System of Multi-Aspect Usage for Buildings and Facilities with Large-Span Structures Industrial and civil construction 1 pp 22-24 (2011).

8. Soldatenko V.S., Harin V. N. Method of substantiating the rational option of monitoring points of the technical condition of engineering systems of unique buildings and structures. Inzhenerno-stroitel'nyj zhurnal 2 pp 47-57 (2014). 